\title{
Land Capability Classification for Crop and Fruit Product Assessment Using GIS Technology. Case Study: The Niraj River Basin (Transylvania Depression, Romania)
}

\author{
Sanda ROȘCA ${ }^{1}$, Ştefan BILAŞCO ${ }^{1,2 *}$, Ioan PĂCURAR ${ }^{3}$, Marcel ONCU ${ }^{1}$, \\ Cornel NEGRUŞIER ${ }^{3}$, Dănuţ PETREA ${ }^{1}$ \\ I "Babeş-Bolyai"University, Faculty of Geography, 400006Cluj-Napoca, Romania; sanda.rosca@geografie.ubbcluj.ro; \\ sbilasco@geografie.ubbchij.ro ("correspondingauthor);oncu@geografie.ubbcluj.ro; dpetrea@geografie.ubbcluj.ro \\ ${ }^{2}$ Romanian Academy, Cluj-Napoca Subsidiary Geography Section, 400015, Cluj-Napoca, Romania \\ ${ }^{3}$ University of Agricultural Science and Veterinary Medicine Cluj-Napoca, 3-5 Mănăştur St., 5400372 Cluj-Napoca, Romania; ioanpacurarc@yahoo.com; \\ cornelnegrusier@gmail.com
}

\begin{abstract}
The efficient capitalisation of agricultural land is dependent on determining the environmental suitability of the area and on identifying the most appropriate culture types for a particular terrain. Because of its complex landforms, the anthropic pressure and the irrational use of land on large surfaces, the Basin of Niraj River was the object of a reorganising process in the production activities, by emphasising the agricultural land use as a resource for sustainable development, which has been too long underexploited. The technique of capability classification, in collaboration with the GIS techniques of spatial analysis, represents one of the most facile and concrete ways of identifying and creating an inventory of lands which fulfil the best conditions for the creation of orchards, through the use of specific indicators: climatic, morphometric, morphologic, pedologic. The present study created a new GIS model of spatial analysis, which could offer a new approach to the classical method of land capability classification. The identification of the areas which are suitable for fruit tree cultivation was based on this model by integrating the specific indicators into databases and GIS spatial analysis equations. The results of this study highlights the maps of the land favorability for apple trees, pear trees, plum trees, cherry trees, peach trees and apricot trees and a geodatabase materialization in the maps of quality classes for orchards.
\end{abstract}

Keywords: crop, database, favourability, GIS modeling, land suitability, land capability

\section{Introduction}

The new national approaches to land management aim mainly the land's agricultural capitalisation (GAEC, 2003; CPPPP, 2015, according to the National (Romania) Strategic Framework for sustainable development of the agro-alimentary sector and the rural area in the interval 2014-2020-2030). In the present context, the research concerned with land suitability for certain types of agricultural use represents a very important stage in the decision process of the local and national authorities.

The economical approach for land capability classification was developed by the German school for the ecological and economical land zonation in 1932, while the Russian school focused on researching and implementing a land classification based on fertility and pedology studies. In the same year, Storie Earl, who was considered the father of the American school of land capability classification, created the Storie system of land classification which considered both the soil characteristics and the natural conditions of the territory (Aparaschivei, 2012).
The land capability classification includes the identification of land suitability for different agricultural uses, as well as the restrictions determined by specific physic-geographical characteristics and is used as a study method for identifying the agricultural potential and the pedo-geographical identity of a territory. The suitability is expressed by means of land capability values in natural conditions and after their enhancement through land improvement measures (according to the Cadastre of Agricultural Fund).

These studies of land capabilities were used by the Soil Conservation Service from USA in 1958 and were adapted for the territory of Romania by Cârstea $(1964,1975)$ according to the I.C.P.A. regulations for solving the problems which are connected to territorial planning (Florea et al., 1987). At present, it is performed according to the Methodological Regulations created by ICPA and OJSPA, vol I and II (1987) and the Methodology of pedological and agro-chemical studies created by the National and County System of Soil-Land Monitoring for Agriculture (Monitorul Oficial, 2002). 
236

Studies concerned with the subject of land capability classification and soil resources were done by Teaci $e t$ al. (1972, 1989), Cernescu et al. (1964, 1994), Florea et al. (1989, 1999), Munteanu et al. (2000), Păcurar and Buta (2007), often focusing on the climate's influence (Berbecel et al., 1984; Untaru and Vespremeanu, 1994). A land capability classification at national level for 455 areas extracted from the map of pedo-climatic microzoning at a scale of 1:1.000.000 (Florea et al., 1999) was created using the BDUTS software by Vlad (2001). The results of various studies draw the attention upon the decrease of land productivity due to climatic changes and the increased surface of degraded land in spite of an increase in the number of inhabitants and thus of necessity (Behzad et al., 2009; Yasmina et al., 2001; Henok, 2010; Păcurar et al., 2013).

The spatial modelling of land suitability to various agricultural cultures requires the use of several techniques and methods of spatial analysis which rely on specialised software and the manipulation of thematic layers by means of mathematical equations transformed into GIS equations, and functions of spatial analysis used to generate new attributes stored in various databases (Petrea et al., 2014).

In the case of the studies which focus on land suitability to various measures of pedologic improvements, it is necessary to create a database to include the characteristics of the soil (soil type, texture, gleying processes etc.), the geormorphologic characteristics of the territory under analysis (slope angle, aspect, elevation), as well as climatic and hydric data (air temperature, precipitation amount etc.) In order to determine the best results possible for the spatial distribution of land suitability to certain cultures, the largest number available of factors is recommended to be included in the GIS models (Van Diepen et al., 1991).

\section{Materials and methods}

\section{Casestudy}

The territory of Niraj river basin (Fig. 1) includes 12 administrative units: 13 communes (Acăţari, Crăciuneşti, Gheorghe Doja, Ungheni), to the eastern (Eremitu, Chiheru de Jos, Găleşti, Măgherani, Bereni, Miercurea Nirajului, Păsăreni, Vărgata, Suplac) and the northern area (Hodoşa) of the Mureş County, and a town (Miercurea Nirajului) which belong to Târgu Mureş metropolitan zone. The whole region has a significant agricultural tradition, its economical activities being tightly connected to the agrarian potential, which is characteristic for the middle and lower sectors of the river basin, and to the forest resources from the upper sector. In the Local Development Plan of the Niraj Valley Microregion (Assoc Leader, 2012), the Niraj Valley is divided into three sectors: the microregion of the Nirajul de Jos Valley, which includes the administrative units of Gheorghe Doja, Ungheni, Crăciunești, Suplac and Acățari, the main land use is represented by vegetable crops and the region is locally called "land of the carrot". The central area of the Niraj Valley, which includes the communes Păsăreni, Găleşti and the corresponding settlements of the Miercurea Nirajului town, is dominated by grain cultures and the area has a higher degree of industrialisation compared to the other regions. The upper sector of the river basin, represented by the settlements included in the communes Bereni, Vărgata and Măgherani, marks the transition to the mountain zone, while Eremitu and Chiheru de Jos stand out through cultivation of fruit trees.

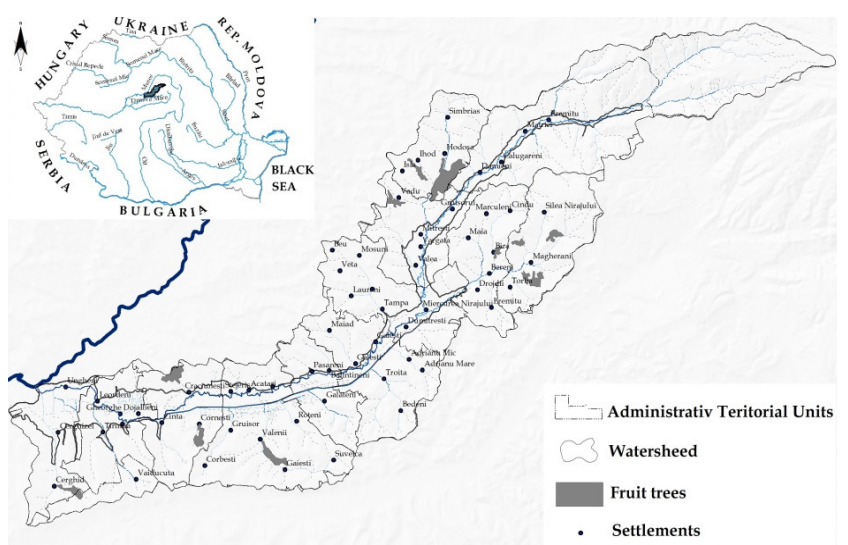

Ffg. 1. Geographical location of the Niraj river Hasing

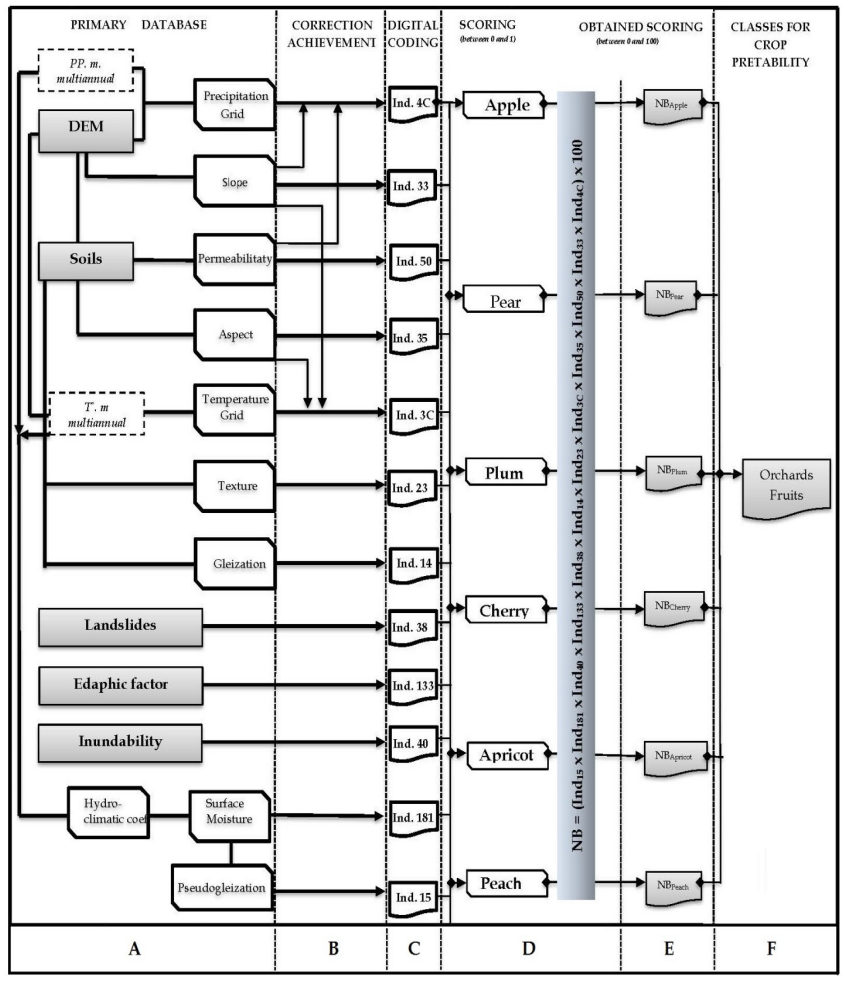

Fig. 2. Methodological flowchart

\section{Databases}

Starting from the analysis of the qualitative soil parameters included in different databases (Table 1), which were obtained based on 1:5000 Topographical Maps and from other modelled database, a GIS spatial analysis model was created to identify the areas in the territory of the Niraj river basin which have the maximum suitability for the creation of fruit tree plantations. The model was developed on primary databases which were modelled and structurally derived according to the classical methods of land capability classification into six categories (Fig. 2).

The first category represented by the primary databases was used as input data in the spatial analysis model and included the characteristics of the topography (raster data structures), the spatial distribution of the average multiannual precipitation and temperature (raster data structures), the soils, landslides, flood zones and edaphic volume (vector databases) (Table 1). 
Table 1. Databases used for the modelling process

\begin{tabular}{|c|c|c|c|}
\hline Database & Structure type & Attributes & Database type \\
\hline DEM & raster & Elevation $(\mathrm{m})$ & primary \\
\hline Slope angle & raster & $\%$ & modelled \\
\hline Aspect & raster & Aspect type & modelled \\
\hline Soils & vector & Type, texture & primary \\
\hline Permeability & raster & measure & modelled \\
\hline Gleying & raster & Gleying classes & modelled \\
\hline Edaphic volume & raster & $\%$ & modelled \\
\hline Texture & raster & Texture type & primary \\
\hline Average multiannual precipitation & raster (grid) & Precipitation (mm) & modelled \\
\hline Average multiannual temperature & raster (grid) & Temperature $\left({ }^{\circ} \mathrm{C}\right)$ & modelled \\
\hline Pseudogleying & raster & Pseudogleying degree & modelled \\
\hline Humidity at the surface & raster & Humidity degree & modelled \\
\hline Landslides & vector & Activity stage & modelled \\
\hline Flood zones & vector & Inundability classes & modelled \\
\hline
\end{tabular}

The preparation of the primary database (methodological stage A) consisted of modelling the average multiannual precipitation and temperature grids using the data from hydrological and weather stations and correlating them with the elevation.

The topographic characteristics which were derived from the digital elevation model represented a modelled database which was used further for extracting the parameters, being included in the spatial analysis. The grid database representing the spatial distribution of the average multiannual precipitation and temperature was generated by identifying the spatial correlation of the climatic parameters with the elevation through a regression and by integrating the equation defining the regression curve as a spatial analysis equation in the GIS environment (Bilasco, 2010).

When analysing the terrain characteristics for practical purposes (in this case, identifying the land suitability for fruit tree plantations), the slope angle was an absolutely necessary parameter. It has morphometrical relevance as a causing factor for various erosion processes, which become restrictive factors for agriculture, and an important role in land management, as it influences accessibility and costs. Using the grid database which was derived from the DEM and considering the suitability classes according to indicator 33 , the thematic map of the slope angle factor and its corresponding database were generated to be eventually used in the spatial analysis equation.

The slope aspect was also a necessary quantitative parameter due to its influence upon the geomorphologic processes which take place on slopes (and act as restrictive factors), through the climatic parameters unequally distributed: solar radiation, insolation, precipitation and temperature.

Another important stage in the model generation was the structuring of the database which included the main soil characteristics: permeability, gleying and the edaphic volume. Taking into consideration the vast area included in the model $\left(658 \mathrm{~km}^{2}\right)$ and the difficulty in acquiring the data associated to these parameters, the values extracted from the national thematic maps were used (Dumitru et al., 2011).

The values of the specific parameters for each homogenous territorial unit were identified using the technique of interpolation applied to the initial values. Due to the fact that the previous studies used as references (Dumitru et al., 2011) offer parameter values (through maps) with a low degree of territorial dispersion $(16 \times 16 \mathrm{~km})$, an interpolation method giving the most accurate results was identified by analysing the compared results of two frequently used methods which approximate intermediate values starting from singular values: the Inverse Distance Weighted method and the Kriging method. Finally, the grid databases were completed as thematic layers representing the indicators 50,14 and 133, by using the interpolation method Kriging universal, as it has reported highly accurate values in the testing and validation stages, as well as in the comparison with the existing subjects.

Landslides (indicator 38), as well as erosion processes and anthropic activity, represent one of the main factors which exclude large land surfaces from agricultural use, with major consequences on land management and the economic development of the affected areas (Petrea $e t$ al., 2014). The database including the position of the active landslides was created by field measurements and the interpretation of recent satellite images.

The inundability indicator (ind. 40) was included in the model after previously determining the flooding zones of the studied territory: frequently floodable (once every 2-5 years), rarely floodable (>5 years) and not floodable (Roșca et al., 2014).

The hydroclimatic coefficient, as a modelled database, started from the average multiannual precipitation and temperature and represented a very important factor in the process of land capability classification, as it creates the basis for generating and spatially distributing two other important indicators: excess of surface humidity (ind. 181) and pseudogleying (ind. 15).

\section{GIS analysis}

Each of the previously mentioned indicators was integrated into a database which included the primary layers of their spatial distribution in the river basin under analysis. The resulting polygons included in their attribute tables quantitative and qualitative data which were coded to facilitate the stages of interrogation, reclassification and overlay. All factors were analysed as GIS databases which were prepared to be integrated in the spatial analysis model.

For some of these indicators a single series of coefficients was used, while for indicators such as air temperature, soil gleying, edaphic volume etc. only corrections of them were used, due to their interdependence with other indicators: the temperature was corrected considering the slope aspect and angle, the precipitation amount was corrected in respect with the slope angle, the degree of soil permeability derived from the soil texture (ind. 
238

23), the excess of surface humidity (ind. 181) was generated by using the corrected values of precipitation and temperature, together with permeability and slope angle (Methodological stage $B)$.

The correction of these indicators was possible by using the attributes of the vector databases which resulted after intersecting the thematic layers as primary databases and sorting them according to the table entries that describe the land use classification.

The geocodification stage (Methodological stage $C$ ) provided appropriate codes for an easier identification of the indicator classes, according to the regulations of land capability classification.

The following modelling stage (Methodological stage D) consisted in attributing land capability values ranging between 0 and 1. Each previously encoded indicator that describe the topographical conditions, the characteristics of the soil and the climatic and hydrologic resources, received such land capability values according to their influence, between 0 and 1 . If a coefficient is considered to be favourable for the analysed culture, it received the maximum capability value (1), which decreased down to 0 for a total restriction of that particular culture.

The instruments of this study were represented by the tables with soil classification criteria, which characterise the land suitability dependent on specific features, and were according to the methodology presented in the synthetic work of Methodology for writing pedologic studies (Florea et al., 1986).

The land capability values for each type of land use (Methodological stage E) were determined using the Overlay technique which enables an integrated spatial analysis of several components (in this case the land capability values / indicator / culture), in order to highlight an essential attribute of the analysed territory - the suitability of the land for the analysed cultures.

The Overlay technique of the type raster-raster was used to identify the most suitable land through the spatial analysis model, which combines in a spatial analysis equation the raster thematic layers as grids representing the modelled and the derived databases created in the previous stages.

The spatial distribution of the land capability values and the localisation of the favourable areas for the analysed cultures required the generation of a spatial analysis equation (1) which included raster databases and relied on mathematical identifiers which allow the software to illustrate the result of the spatial analysis.

("Ind15"* "Ind181"* "Ind40"* "Ind133"* "Ind38”* "Ind14"* "Ind23" * “Ind3C" * "Ind35” * "Ind50" *"Ind33" * "Ind4C") * 100 (1)

where:

"Ind..." - The raster database representing the coded indicator.

*-The mathematical identifier for multiplication.

Where the land capability value was at its maximum (100), the territory was characterised by topography, type of soil and specific climatic and hydrologic factors which do not limit in any way the development of the analysed culture, on the contrary, they offer the best conditions for it. When one or more coefficients have been penalised for restrictive influence, the final land capability value is to be smaller than 100, describing less favourable conditions. The value 0 of the land capability can also be used when even one of the indicators is considered to be unfavourable.
As a result, the maps of agricultural land use favourability, materialised into spatially distributed databases, illustrated the land capability values for various measurable traits, significant indicators which were mapped at local and regional scale. Maps for each of the corresponding coefficients of the indicators previously presented were generated, in order to determine the land capability values for each of the following fruit tree cultures: apple, pear, plum, cherry-sour cherry, apricot and peach.

\section{Results and discussions}

For the spatial analysis model to be completed, the analysis of the databases and of the specific thematic maps for the 12 indicators was necessary. For each indicator the specific intervals and the favourability class defined by national studies were identified.

The favourability of the terrain for fruit tree plantations was assessed for the entire river basin starting from the GIS databases and the data manipulation. For a more detailed view, the data and the resulting maps were also illustrated at the local level. The methodology for pedologic studies which are to be used in the projects of territory organisation and systematisation recommend the use of the 1:10000 - 1:25000 scale, depending on the complexity of the analysed territory. The maps and the additional data thus created represent a database including qualitative spatial information with predictive role.

Table 2 illustrates the classes of favourable physicogeographical factors for various fruit tree cultures which received the maximum land capability value of 1 .

In the category of restrictive factors for fruit tree plantations in the analysed territory were distinguished the following classes (Table 3), which received a low land capability value: $0,0.1$ or 0.2 .

In the case of the Niraj river basin the climatic factors were considered unfavourable for apricot and peach tree cultures.

According to formula (1) which was presented in the methodological section, the spatial distribution of the fruit tree favourability was determined (Fig. 3A, Fig. 3B, Fig. 4A, Fig. 4B, Fig. 5A, Fig. 5B). For all images, classes I indicate a very good favourability with a good predictability of orchard, Classes II indicate a good favourability, classes III indicate a medium favourability, classes IV characterised the area with low favourability to orchards and the $\mathrm{V}^{\text {th }}$ classes are the areas with severe restriction to this land use.

The databases illustrated as maps in Figs. 3, 4 and 5 were included in a complex equation of spatial analysis, specific to geoinformatical softwares, in order to identify the favourable areas for orchards. The equation was completed with the use of mathematical indicators.

In order to describe the territory using favourability classes with a focus on orchards, formula (2) was used in a GIS environment:

$$
\begin{aligned}
& \text { ("NBApple" + "NBPear" + "NBPlum" + "NBCherry" + } \\
& \text { "NBApricot"+"NBPeach")/6 }
\end{aligned}
$$

where:

"NB..." - grid raster data representing the land capability values for fruit tree cultures.

,$+ /$ - mathematical indicators.

The result of the formula (2) consisted of a raster database with numerical attributes ranging between 1.5 and 89.81, the values being reclassified according to the favourability classes (Fig. 6). In the studied area the analysis of the final map highlights the large spatial expansion of the $3^{\text {rd }}$ class of favourability ( $42.62 \%$ of 
Table 2. Land capability and favourable factors for specific fruit trees cultures

\begin{tabular}{|c|c|c|c|}
\hline Favourable factor & Description & Code & Land use \\
\hline \multirow{3}{*}{$\begin{array}{l}\text { Corrected average multiannual temperature } \\
\text { (Ind. 3C) }\end{array}$} & medium T.; $6.1-8^{\circ} \mathrm{C}$ & 06.5 & - \\
\hline & high T.; 8.1-9 ${ }^{\circ} \mathrm{C}$ & 08.5 & cherry-sour cherry trees \\
\hline & high T.; $9.1-10^{\circ} \mathrm{C}$ & 09.5 & pear, plum, cherry-sour cherry and apricot tree \\
\hline \multirow{3}{*}{$\begin{array}{l}\text { Corrected average multiannual precipitation } \\
\text { (Ind. 4C) }\end{array}$} & sub-medium PP.; 501-600 mm/year & 0525 & pear, plum, cherry-sour cherry and apricot tree \\
\hline & medium PP.; 601-700 mm/year & 0650 & apple, pear, plum trees \\
\hline & PP. sub-medium; 701-800 mm/year & 0750 & apple trees \\
\hline \multirow{2}{*}{ Soil gleying (Ind.14) } & non gleic & 0 & all fruit trees \\
\hline & moderately gleic & 3 & - \\
\hline \multirow{4}{*}{$\begin{array}{l}\text { Soil pseudogleying } \\
\text { (Ind. 15) }\end{array}$} & absent & 0 & all fruit trees \\
\hline & weak...strong & 1 & all fruit trees \\
\hline & absent-weak & 2 & all fruit trees \\
\hline & absent-moderated & 3 & - \\
\hline \multirow{6}{*}{ Soil texture in the first $20 \mathrm{~cm}$ (Ind. 23) } & varied & $20-23$ & apricot-sour cherry, peach-apricot trees \\
\hline & silt-sandy & 30 & plum, apricot-sour cherry, peach-apricot trees \\
\hline & silt-sandy; silt-clay; silt-sandy; silty & $41-42$ & all fruit trees \\
\hline & silt-clay & 50 & \\
\hline & silt-clay-clay & 51 & apple, pear, plum trees \\
\hline & silt-clay & 52 & \\
\hline \multirow{2}{*}{$\begin{array}{l}\text { Slope angle } \\
\text { (Ind. 33) }\end{array}$} & horizontal $\leq 2 \%$; slightly sloped $2.1-5 \%$ & $01-03$ & all fruit trees \\
\hline & slightly sloped; $5.1-10 \%$ & 07 & $\begin{array}{l}\text { apple, pear, plum, apricot-sour cherry, peach- } \\
\text { apricot trees }\end{array}$ \\
\hline $\begin{array}{l}\text { Landslides } \\
\text { (Ind. 38) }\end{array}$ & no landslides & 0 & all fruit trees \\
\hline \multirow{2}{*}{$\begin{array}{l}\text { Overflowing inundability } \\
\quad \text { (Ind. 40) }\end{array}$} & not floodable & 0 & all fruit trees \\
\hline & $\begin{array}{c}\text { rarely floodable } \\
(>\text { once every } 5 \text { years })\end{array}$ & 1 & - \\
\hline $\begin{array}{l}\text { Edaphic volume } \\
\text { (Ind. 133) }\end{array}$ & $\begin{array}{c}\text { large } \\
(76-100 \%)\end{array}$ & 088 & plum, peach, apricot trees, vineyard \\
\hline \multirow{3}{*}{ Excessive surface humidity (Ind. 181) } & practically null & 1 & all fruit trees \\
\hline & weak (potential) & 2 & - \\
\hline & moderate & 3 & - \\
\hline
\end{tabular}

the river basin) which is specific to the middle and low sectors of the river basin, represented mainly in the hilly area. The first and second favourability classes represent $6.6 \%$ respective $12.29 \%$ of the territory and are located in the low and middle river basin sectors, especially in the flood area of the Niraj river and in the Târnave low hills. The $4^{\text {th }}$ and $5^{\text {th }}$ classes represent $1.22 \%$ and $37.25 \%$ of the territory, respectively, and mostly characterise the mountain and foothill area of the Gurghiu Mountains in the upper sector of the river basin.

For a better integrated management of the land, the results were further analysed at the level of the administrative units using the spatial identification and the spatial expansion of the various favourability classes (Table 4).

Six favourability classes corresponded to the five quality classes: the first class included lands without limitations and restrictions. This characterised $20 \%$ of the administrative territory of the Suplac commune and only $4.4 \%$ and $4.1 \%$ from the surfaces of Gheorghe Doja and Crăciunești, respectively. A large part of the analysed territory was included in the favourability classes 2 , representing lands with slight limitations and restrictions (65\% of Ungheni, $58.6 \%$ of Gheorghe Doja etc.) and 3 , representing lands with moderate limitations and restrictions (63\% of Magherani, 58.3\% of Hodoșa).

The classes with limitations and restrictions were class 4 , lands with severe limitations and restrictions, and class 5, lands with very severe limitations and restrictions; the land can be corrected and have a higher spatial expansion in Chiheru de Jos (32.3\%) and Eremitu (20.4\%). The $6^{\text {th }}$ class included lands with severe limitations and restrictions that cannot be corrected; this was largely extended in Chiheru de Jos.
Table 3. Restrictive factor classes for fruit trees

\begin{tabular}{|c|c|c|c|c|}
\hline $\begin{array}{l}\text { Favourable } \\
\text { factor }\end{array}$ & Description & Code & $\begin{array}{c}\text { Land } \\
\text { capability } \\
\text { value }\end{array}$ & Land use \\
\hline \multirow{3}{*}{$\begin{array}{l}\text { Corrected } \\
\text { average } \\
\text { annual } \\
\text { temperature } \\
\text { (Ind. 3C) }\end{array}$} & \multirow{2}{*}{$4.1-5^{\circ} \mathrm{C}$} & \multirow{2}{*}{04,5} & 0 & $\begin{array}{l}\text { apricot, peach trees, } \\
\text { vineyard-wine }\end{array}$ \\
\hline & & & 0.1 & $\begin{array}{l}\text { pear, plum, cherry- } \\
\text { sour, cherrytrees }\end{array}$ \\
\hline & $6.1-7^{\circ} \mathrm{C}$ & 06,5 & 0.1 & $\begin{array}{l}\text { apricot trees, vineyard- } \\
\text { wine, vineyard-grapes }\end{array}$ \\
\hline \multirow{3}{*}{$\begin{array}{l}\text { Slope angle } \\
\text { (Ind. 33) }\end{array}$} & $\begin{array}{l}\text { Highly sloped } \\
(25.1-50 \%)\end{array}$ & 30 & 0.2 & $\begin{array}{l}\text { apricot, peach, apricot } \\
\text { trees }\end{array}$ \\
\hline & \multirow{2}{*}{$\begin{array}{l}\text { Very highly } \\
\text { sloped } \\
(50.1-87 \%)\end{array}$} & \multirow[t]{2}{*}{75} & 0.1 & $\begin{array}{l}\text { pear, apricot, sour } \\
\text { cherry, peach, apricot } \\
\text { trees }\end{array}$ \\
\hline & & & 0.2 & $\begin{array}{l}\text { apple, pear, apricot, } \\
\text { sourcherry trees }\end{array}$ \\
\hline
\end{tabular}

\section{Model validation}

The prediction rate of the final results was determined through the validation stage of the spatial analysis model, by comparing the results with the reality in the field for two randomly selected cases: one for the $1^{\text {ts }}$ class of favourability and another for the $5^{\text {th }}$ class of favourability (Fig. 7).

The first comparison (I) concerned an area of $57.28 \mathrm{~m}^{2}$ included in the administrative territory of Cerghid and was characterised by the first class of favourability. As seen in Fig. 7, it is an important area, representing approximately $89 \%$ of the total territory included in the first favourability class, and even more it overlaps an existing orchard. The remaining $11 \%$ were occupied with built up areas having administrative or access purposes, a 
240

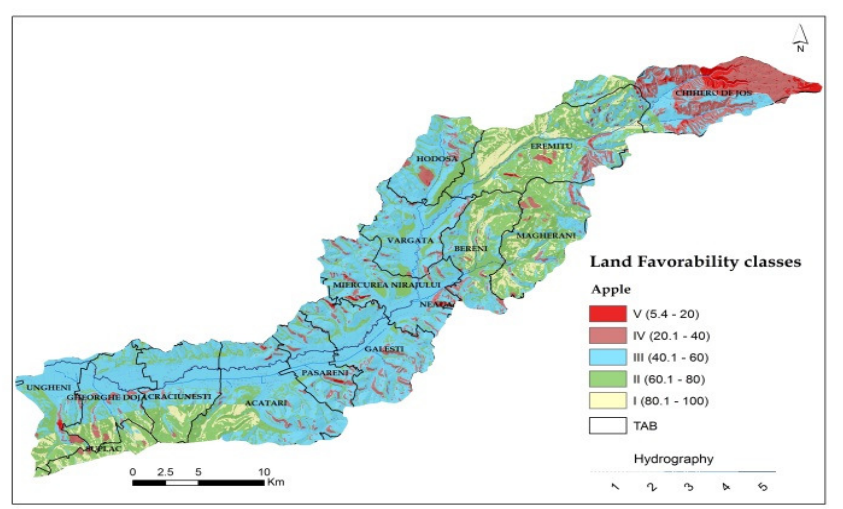

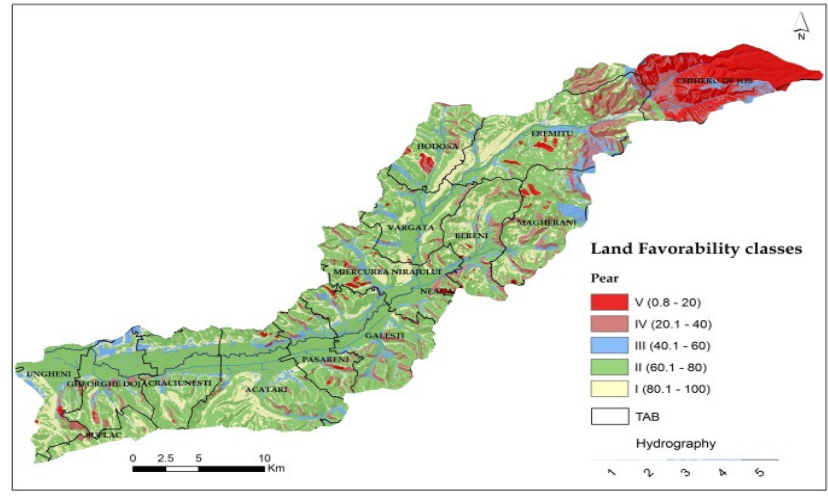

Fig. 3. Quality classes for apple trees (A) and pear trees (B) at the river basin and communal level
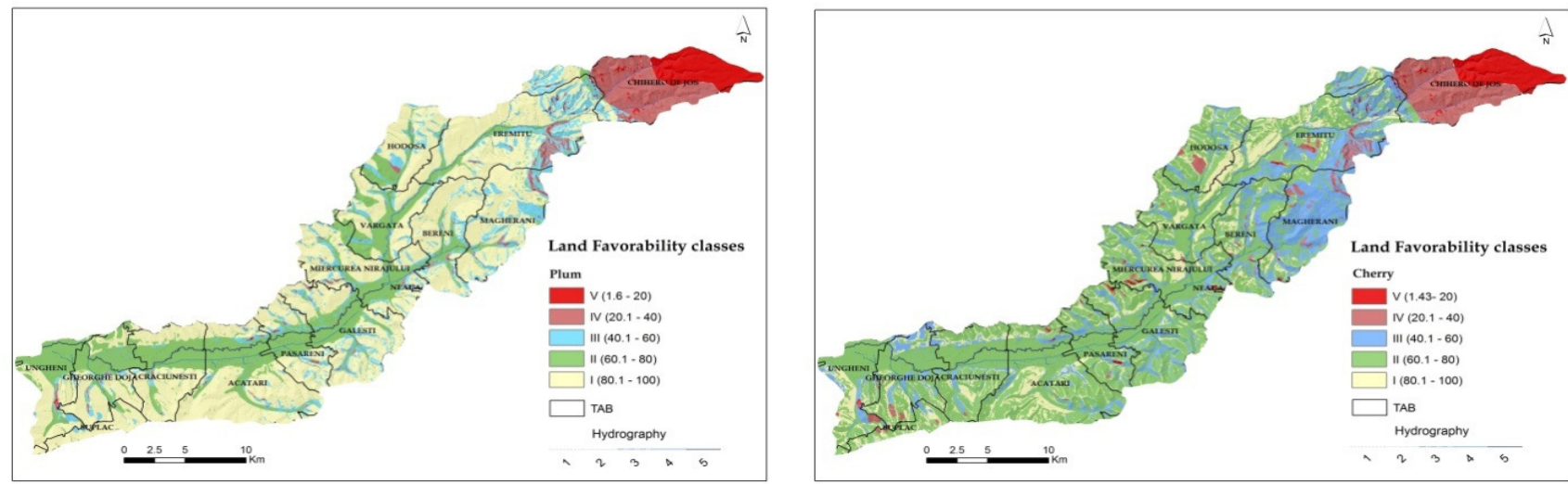

Fig. 4. Quality classes for plum trees (A) and cherry trees (B) at the river basin and communal level
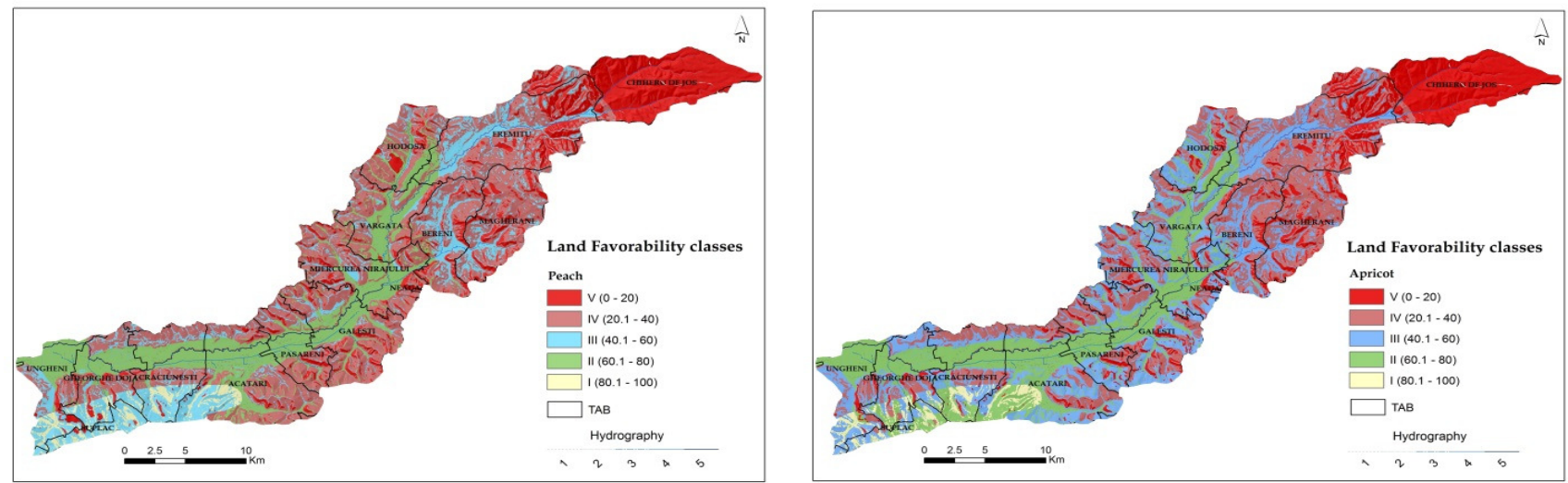

Fig. 5. Quality classes for peach trees (A) and apricot trees (B) at the river basin and communal level

large portion representing favourable land, but not being at present included in the orchard land use class.

The second validating comparison $(\mathrm{V})$ was performed for the entire territory included in the $5^{\text {th }}$ class of favourability, which was exclusively located in the mountain area, in the western part of the settlement, Câmpu Cetății.

The validation rate of the model results was approximately $98 \%$ for the $\mathrm{V}^{\text {th }}$ classes of favourability, which coincided with forest areas (Fig. 7) or highly sloped areas, which are characteristic to the foothill sector.

Considering the fact that the validation rate of the entire model was approximately $93.5 \%$, one can state that the generation of the databases, their accuracy and the employed methodology are suitable for further application of the model in other study cases with similar characteristics of the territory.

Taking into consideration the high number of the factors included in the database it is necessaries to obtain a complete database with a low degree of subjectivity. The advantages of using this method based on G.I.S. model in different areas on the Romanian territory offers the possibility of comparing or combining the resulting maps for a national image of favorability to orchards.

\section{Conclusions}

The innovative land capability classification using GIS spatial models was applicable to mapping areas characterised by various favourability classes and not only punctually classifying certain 
Table 4. Spatial distribution of the favourability classes at the level of administrative units

\begin{tabular}{|c|c|c|c|c|c|c|c|c|c|c|}
\hline \multirow{3}{*}{ Commune } & \multicolumn{10}{|c|}{ Favourability class for orchards } \\
\hline & \multicolumn{2}{|c|}{ I } & \multicolumn{2}{|c|}{ II } & \multicolumn{2}{|c|}{ III } & \multicolumn{2}{|c|}{ IV } & \multicolumn{2}{|c|}{ V } \\
\hline & $\mathrm{m}^{2}$ & $\%$ & $\mathrm{~m}^{2}$ & $\%$ & $\mathrm{~m}^{2}$ & $\%$ & $\mathrm{~m}^{2}$ & $\%$ & $\mathrm{~m}^{2}$ & $\%$ \\
\hline Hodoşa & 0 & 0 & 9919600 & 30.90 & 18740300 & 58.38 & 3393300 & 10.57 & 45700 & 0.14 \\
\hline Eremitu & 0 & 0 & 23989300 & 30.16 & 38249500 & 48.09 & 16266200 & 20.45 & 1040400 & 1.31 \\
\hline Măgherani & 0 & 0 & 9390600 & 19.69 & 30334700 & 63.61 & 7818500 & 16.40 & 142900 & 0.30 \\
\hline Vărgata & 0 & 0 & 17536500 & 45.86 & 18632200 & 48.72 & 2067500 & 5.41 & 4300 & 0.01 \\
\hline Miercurea Nirajului & 0 & 0 & 18980700 & 36.81 & 27209900 & 52.77 & 4841700 & 9.39 & 528900 & 1.03 \\
\hline Chiheru de Jos & 0 & 0 & 1404500 & 2.12 & 5198300 & 7.85 & 21412500 & 32.32 & 38240600 & 57.72 \\
\hline Bereni & 0 & 0 & 13134100 & 33.29 & 21593300 & 54.74 & 4589000 & 11.63 & 132700 & 0.34 \\
\hline Găleşti & 0 & 0 & 18424800 & 34.20 & 30319000 & 56.27 & 4957400 & 9.20 & 175400 & 0.33 \\
\hline Păsăreni & 0 & 0 & 11532200 & 40.03 & 14367200 & 49.87 & 2716800 & 9.43 & 192700 & 0.67 \\
\hline Ungheni & 2040600 & 6.45 & 20812200 & 65.79 & 6706700 & 21.20 & 1732700 & 5.48 & 340300 & 1.08 \\
\hline Gheorghe Doja & 1586700 & 4.42 & 21051300 & 58.64 & 10722700 & 29.87 & 2489100 & 6.93 & 50200 & 0.14 \\
\hline Acățari & 231600 & 0.36 & 34360800 & 52.73 & 28018800 & 42.99 & 2447000 & 3.75 & 109700 & 0.17 \\
\hline Suplac & 2061400 & 20.51 & 7081900 & 70.47 & 424000 & 4.22 & 481900 & 4.80 & 0 & 0.00 \\
\hline Crăciunești & 1676900 & 4.11 & 23740200 & 58.18 & 14203500 & 34.81 & 1177400 & 2.89 & 6700 & 0.02 \\
\hline
\end{tabular}

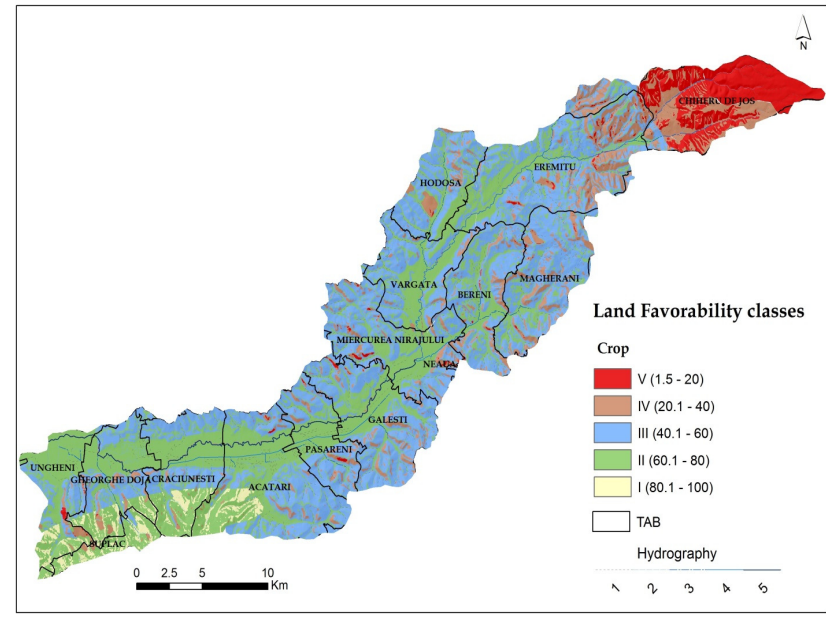

Fig. 6. Quality classes for orchards at the river basin and communal level

land surfaces. The final results can be statistically analysed in relation to their spatial distribution inside the natural (in this case, the Niraj river basin) and the administrative territorial units (by analysing at the commune level the most suitable land uses that were identified by the model), in order to reach the most appropriate decisions for the integrated management of the agricultural land. By integrating a GIS approach through the spatial analysis models in the land capability classification, the results acquired a better accuracy which enables them to be spatially and not only punctually analysed. Furthermore, the integration of land capability indicators in GIS databases made them better manageable and the process of land capability classification required a shorter time for completion, even if the land capability values needed to be adjusted and readjusted in the process. The model was conceived as a "white box" model and, thus, the modelling stages were easy to follow, as well as the identification of the responsible modules for any invalid results. The applied and validated model presented in this study can be successfully extended to identify the areas with various degrees of favourability for all the cultures included in the classical methodology.

\section{Acknowledgements}

This paper is made and published under the aegis of the Research Institute for Quality of Life, Romanian Academy as a part of programme co-funded by the European Union within the Operational Sectorial Programme for Human Resources Development through the project for Pluri and interdisciplinary in doctoral and post-doctoral programmes Project Code: POSDRU/159/1.5/S/141086.

\section{References}

Aparaschivei O (2012). Quantitative determination of ecologic indices used for capability classification of mountain and premountain beech forests (FM1+FD4) in the Baraolt and Bodoc Mountains. PhD thesis, Transylvania University from Brașov (in Romanian).

Assoc Leader (2012). Local development plan of the Niraj Valley Microregion. RetrievedJan 14,2015, from http://www.valeanirajului.ro/.
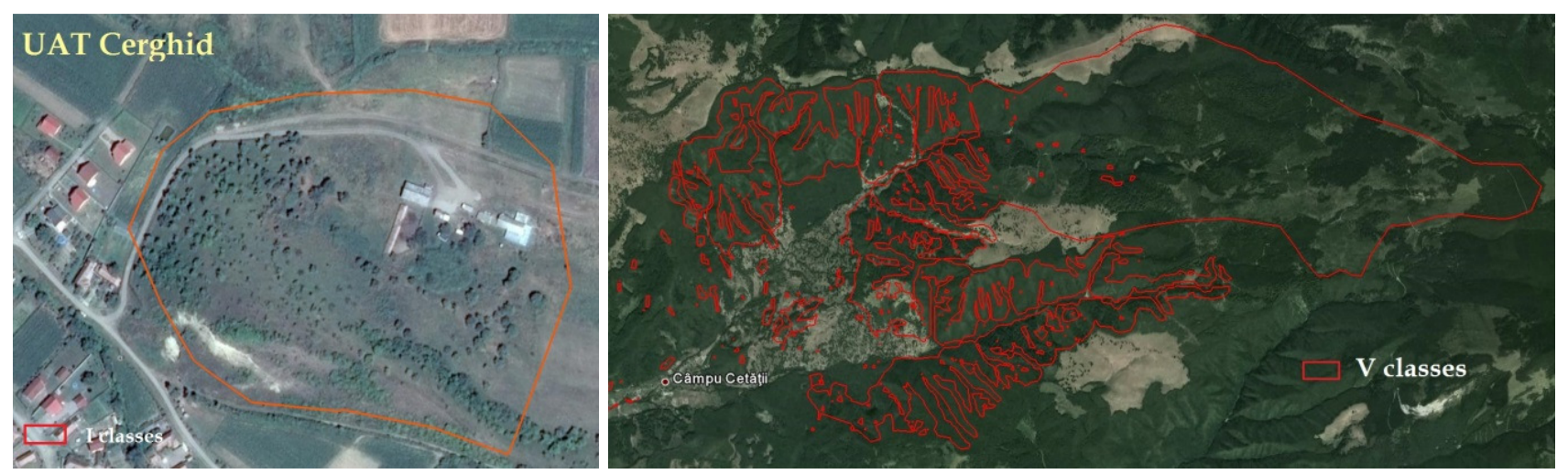

Fig. 7. Spatial distribution of the favourability classes at the level of administrative units 
Behzad M, Albaji M, Papan P, Nasab SB, Naseri AA, Bavi A (2009). Qualitative evaluation of land suitability for principal crops in the Gargar Region, Khuzestan Province, Southwest Iran. Asian J Plant Sci $8(1): 28-34$.

Berbecel O, Eftimescu M, Mihoc C, Socor E, Cusursuz B (1984). Research on the agro-climatic resources of the Socialist Republic of Romania. Informative Bulletin ASAS 13:33-43.

BilașcoȘT (2010). GIS model for achieving the spatial correlation between average multi-annual precipitations and altitude. Studia Universitatis Babes-Bolyai, Geographia Liv 2:71-78.

Cârstea D, Binder A, Strieter R, Boberschmidt L, Thomas L, Golden J (1975). Guidelines for the environmental impact assessment of small structures and related activities in coastal bodies of water. Prepared by MITRE Corporation for US Army Corps of Engineers, New York District.

Cârstea S (1964). Utilization of soil survey in land capability classification for various agricultural uses. VIII ${ }^{\text {th }}$ Internaţional Congres of Soils Science, vol 5.

Cernescu N, Florea N et al. (1964-1994). Soil map of Romania, scale 1:200.000. Geologic Institute of Pedologic and Agro-Chemical Research, Bucureşti (in Romanian).

CPPPP (2015). Presidential Commission on Agricultural Development Public Policy - The National Strategic Framework for sustainable development of the agro-alimentary sector and the rural area in the interval 20142020-2030 (in Romanian). Retrieved Febr 4, 2015, from http://www.presidencyro/static/Cadrul\%20National\%20Strategic\%20Rural.pdf.

Dumitru M, Dumitru S, Tănase V, Mocanu V, Manea A, Vrînceanu N, Preda M, Eftene M, Ciobanu C, Calciu I, Rîşnoveanu I (2011). The monitoring of soil quality in Romania. Sitech Publicher, Craiova (in Romanian).

Florea N, Bălăceanu V, Răuță C, Canarache A (1986). Soil assessment

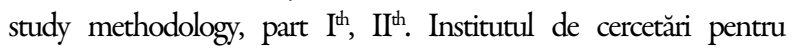
Pedologie şi Agrochimie (in Romanian).

Florea N, Bălăceanu V, Răuță C, Canarache A (1987). Soil assessment study methodology (MESP). Part IIIt ${ }^{\mathrm{h}}$ Ecopedological Indicators. Redacția de propagandă tehnică agricolă, ICPA, Bucureşti 226 p (in Romanian).

Florea N, Untaru G, Berbecel O, Teaci D, Tudor A, Răuță C, Canarache A (1989). The pedo-climatic microzonation of the Socialist Republic of Romania's territory. An ICPA 49:11-37.

Florea N, Untaru G, Vespremeanu R (1999). The updated pedo-geoclimatic microzonation of Romania's territory. Soil Studies 33(1):86104 (in Romanian).

GAEC (2003). GAEC Good Agriculture and Environment Conditions nr. 1789/2003. Retrieved February 12, 2015, from

http://marswiki.jrc.ec.europa.eu/wikicap/index.php/Good_Agricult ural_and_Environmental_Conditions_\%28GAEC\%29.

Henok M (2010). Land suitability and crop suitability analysis using remote Sensingand GIS application. A case study in Legamboworeda, Ethiopia.
Hunting H (1976). Tigray rural development report. Hemel Hempstead, Hertfordshire, UK: Central Highlands of Ethiopia. $\mathrm{PhD}$ Thesis Universitat Hohenheim (310) D-70593 Stuttgart.

Monitorul Oficial (2002). Governmental Order no. 598, August 13, 2002 (in Romanian).

Munteanu I, Dumitru S, Mocanu V, Moise I (2000). The land types from Romania at a scale of 1:2.500.000 after SOTER methodology and their use in fundamenting the conservation and land fund protection strategy. Symposium works "Environmental protection in agriculture" București 1:102-111.

Pacurar I, Bilaşco Ș, Cristina CM, Dîrja M, Moldovan IC, Păcurar HM, Lucaci A, Negruşer C (2013). Research on identification of degraded lands in Transylvanian Plateau using GIS spatial analysis.. ProEnvironment/ProMediu 6(14):216-226.

Păcurar I, Buta M (2007). Pedology and agricultural land capability classification, Applications. Ed AcademicPres Cluj-Napoca (in Romanian).

Petrea D, Bilaşco Ş, Roşca S, Vescan I, Fodorean I (2014). The determination of the landslide occurrence probability by spatial analysis of the land morphometric characteristics (case study: The Transylvanian Plateau). Carpathian J Earth Environm Sci 9:91-110.

Roșca S, Petrea D, Bilaşco Ș, Rus I, Irimuş IA, Fodorean I, Vescan I (2014). Assessment of flood hazard and risk using Gis and historical data. Case-study: The Niraj River Basin (Transylvania Depression, Romania). Informatics, Geoinformatics and Remote Sensing, Conference Proceedings-Photogrametry and Remote Sensing, Cartography and GIS 3:497-504.

Teaci D, Popescu I (1972). Pedo-climatic zoning of agricultural land in the Socialist Republic of Romania scale 1:500.00. ICPA, Bucureşti.

Teaci D, Toncea I, Hartia S, Tudor A, Ciorlăuş A, Vlăduțiu I, Georgescu D, Ionescu E, Lup A, Călugăru M (1989). Ecological and economicotechnological models in natural ecosystems and intensive zonal agroecosystems. An ICCPT 67:315-332.

Untaru G, Vespremeanu R (1994). Additional data for characterising pedo-climatic microzones. Technical Report ICPA, Bucureşti (in Romanian).

Van Diepen CA, Van Keulen H, Wolf J, Berkhout JAA (1991). Land evaluation: from intuition to quantification. In: Stewart BA (Ed), Advances in Soil Science. Springer, New York pp 139-204.

Vlad V (2001). Contributions to decision support systems for the evaluation and use of agricultural lands, $\mathrm{PhD}$ Thesis, USAMV Bucureşti (in Romanian).

Yasmina A, Moulay A, Najmia AM, Enrico B, Yasmina B, Paolo Omar C, Aldo D (2000). Land evaluation in the province of Ben Slimane, Morocco. Proc. of 21st Course Professional Master Remote Sensing and Natural Resource Evaluation 21:62-78. 